\title{
Interaction Between Pre- and Post-Migration Factors on Depressive Symptoms in New Migrants to Hong Kong from Mainland China
}

\author{
Kee-Lee Chou • Winky K. F. Wong • \\ Nelson W. S. Chow
}

Received: 11 August 2009/Accepted: 26 June 2010/Published online: 7 July 2010

(C) The Author(s) 2010. This article is published with open access at Springerlink.com

\begin{abstract}
The goal of the current study is to examine the role of poor migration planning as a moderator for the effects of two post-migration factors, namely acculturation stress and quality of life, on symptoms of depression. Using a random sample of 347 Hong Kong new migrants from a 1-year longitudinal study, we used multiple regression analyses to examine both the direct and interaction effects of poorly planned migration, acculturation stress, and quality of life on depressive symptoms. Although poorly planned migration did not predict depressive symptoms at 1-year follow-up, it did exacerbate the detrimental effect of the two post-migration factors, namely high stress or low quality of life (both also measured at baseline) on depressive symptoms at this stage. Our results indicate that preventive measures must be developed for new immigrants in Hong Kong, especially for those who were not well prepared for migration.
\end{abstract}

Keywords Depression - Migration - Quality of life · Stress

\section{Introduction}

Increasing rates of migration throughout the world have led to a growth of interest in its impact on migrants' mental health (United Nations 2006). Although it is well-established that successful adaptation after resettlement for asylum seekers and refugees involves a complex interaction

K.-L. Chou $(\bowtie) \cdot$ W. K. F. Wong · N. W. S. Chow Department of Social Work and Social Administration, The University of Hong Kong, Pokfulam Road, Hong Kong, China

e-mail: klchou@hku.hk between the pre- and post-migration experience (Birman and Tran 2008; Fenta et al. 2004; Lindencrona et al. 2008; Silove et al. 1997), little is known about how these two sets of factors interact among new immigrants whose motivation to move is the desire to reunite with family. Specifically, poorly planned migration, one of the possible premigration factors, has been found to be associated with depression among Irish migrants living in London; furthermore, social support has been shown to moderate the impact of such poor preparation on depression in a crosssectional case-control study (Ryan et al. 2006). However, the interaction between pre- and post-migration factors is not a static process. This report provides a more complete evaluation of this interaction by examining the interrelationships between a pre-migration factor (preparation); two post-migration factors (acculturation stress and quality of life); and an outcome variable, namely symptoms of depression. This is achieved using a longitudinal study of a random sample of immigrants newly arrived in Hong Kong from Mainland China. In particular, we test the interaction effect between the pre- and the two post-migration factors on symptoms of depression.

Because of the "one country, two systems" policy, Hong Kong is considered a part of Mainland China, but residents of the latter need to apply for two-way and oneway permits to temporarily stay or permanently reside, respectively, in Hong Kong. Over the past two decades, from 1985 to 2004, new arrivals from the Mainland admitted under the One Way Permit (OWP) scheme have contributed a total population growth of $54.9 \%$. Specifically, a total of 807,431 Mainland residents have been admitted under the OWP scheme during this period, equivalent to approximately $11.7 \%$ of the population of 6.92 million in 2004. The main purpose of the OWP scheme is family unification. Of the daily quota of 
150 OWPs, 60 are allocated to children born in the Mainland to Hong Kong residents and 30 to Mainland residents who have been separated from their spouses (usually their husbands) for 10 or more years. Therefore, not surprisingly, these new arrivals are either the children (about $30 \%$ ) or wives (about 27\%) of Hong Kong residents who wish to rejoin their families. Given the extremely low local fertility rate of recent years, new arrivals from the Mainland now form the single most important source of population inflow, and are shaping Hong Kong's demographic growth and composition. As the current policy allows some 55,000 (that is, $150 \times 365$ ) Mainland residents to migrate to Hong Kong annually under the OWP scheme, coupled with more than 10,000 known crossboundary marriages every year, it is likely that the scheme will remain the most important source of population increase for the foreseeable future. An examination of the impact of pre- and post-migration factors on the depressive symptomatology of these new arrivals is therefore pivotal to the prevention of mental health problems among this subsection of the population.

Geographic proximity and a shared written language have always meant that migration from the Mainland to Hong Kong has been relatively simple and inexpensive. However, this is not the case for new arrivals from the Mainland because very often it takes 5-10 years for an adult to get a one-way permit after filing an application. Therefore, it can be presumed that new arrivals from the Mainland to Hong Kong are unlikely to undertake migration without having first done at least some prior planning. On the other hand, the passage of time in itself does not guarantee adequate planning, and the long wait may lead to the deterioration of hope among potential migrants. Chou has previously found that poorly planned migration is a significant predictor of symptoms of depression among Mainland China migrants to Hong Kong (Chou 2009), but that social support reduced its harmful effect, based on cross-sectional data. The present study has two specific aims. Firstly, we sought to test whether poorly planned migration would result in more symptoms of depression after first a period of several months, and then of 1 year, of residence in Hong Kong. Secondly, we aimed to examine how poorly planned migration might exacerbate the effect of acculturation stress and quality of life on symptoms of depression.

\section{Methods}

\section{Data Source}

The target respondents in this study were new immigrants aged 18 and older. To be eligible, a respondent was required to have come from the Mainland on a one-way permit for the purposes of ordinary residence in Hong Kong, and to have lived in Hong Kong for between 3 and 6 months. Each new migrant has to apply for a Hong Kong Identity Card at the Registration of Persons-Kowloon Office within 30 days of arrival. In November 2006, using systematic random sampling, our interviewers approached each potential respondent at that office; if the person was eligible they were asked to participate in the survey. During this month, we successfully recruited 613 potential respondents but only 569 were found to be eligible, the reason for exclusion being failure to meet the age criterion. Of these 569 eligible respondents, 501 agreed to participate. Because almost all new migrants apply for their Hong Kong Identity Card at the Kowloon Office in the week following their arrival, and one of the inclusion criteria for our respondents was that they must have been resident in Hong Kong for at least 3 months, we contacted these potential respondents 4 months later and arranged face-toface interviews with them. During the period between March 1, 2007 and April 30, 2007, we successfully interviewed 449 out of these 569 eligible respondents, a response rate of $78.9 \%$. One year later, 347 of these respondents were interviewed for a second time. This represented $80 \%$ of those identified at the earlier baseline who were still living in Hong Kong at the time of the follow-up interview. Non-response did not vary significantly by age, gender, or other known characteristics of the respondents. No respondent had a prior history of depression.

\section{Measure}

The severity of symptoms of depression was assessed at both baseline and follow-up, using a standardized measure, namely the 20-item Center for Epidemiological Studies of Depression (CES-D) scale developed by Radloff (1997), and its validated Chinese version (Chou and Chi 2001). It asks participants about the frequency of depressive symptoms experienced during the 1 -week period preceding the interview. Frequency is assessed on a standard 4-point scale where $0=$ none, $1=1$ or 2 days a week, $2=$ 3-4 days per week, and $3=5$ days or more per week. The scale score was calculated as the unweighted sum of the 20-component item, with a potential range from 0 to 60 . The internal reliability (Cronbach's $\alpha$ ) of the Chinese version of the CES-D applied to the present sample was 0.73 .

To assess preparation for migration, we asked eight questions, which had been used in a previous study (Ryan et al. 2006; Chou 2009). These covered whether or not participants had done any of the following; discussed their migration with family members in Mainland China; 
obtained family agreement for their decision; pre-arranged employment in Hong Kong; considered their total length of stay; pre-arranged accommodation; and made any kind of preparation for their migration. It also asked whether they had a network of friends or family available to give them support upon arrival, and what their principal reason was for leaving the Mainland. Preparation for migration was calculated as the sum of the negative answers to the eight questions. The resulting total score had moderate internal consistency (Cronbach's $\alpha=0.72$ ).

Our measure of acculturation stress in the social, attitudinal, familial, and environmental contexts was based on a standardized 26-item measure, namely the Social, Attitudinal, Familial, and Environment (SAFE) Acculturation Stress Scale developed by Hovey and Magana (2000) and validated within the local context (Wong et al. 2004; Chou 2009). Respondents rated each item on a 6-point Likert scale ranging from $0=$ not stressful to $5=$ extremely stressful. The scale score was calculated as the unweighted sum of the 26 items, with a potential range from 0 to 130 . The internal reliability (Cronbach's $\alpha$ ) of the Chinese version of the SAFE Acculturation Stress Scale in the present sample was 0.79 .

The Hong Kong Chinese version of the World Health Organization Quality of Life (WHOQOL) Scale-Brief Version was also used to assess quality of life across four domains including physical health, psychological health, social relationships, and environment, based on the earlier WHOQOL-100 (World Health Organization Quality of Life Group 1998). The psychometric properties of this 28item scale have been found to be good (Chan et al. 2006). Participants were asked to rate themselves on a 5-point Likert scale ranging from 1 to 5 . The total scores of the WHOQOLS were calculated as the unweighted sum of the 28-component item, with a potential range from 28 to 784 . The internal reliability (Cronbach's $\alpha$ ) of the Chinese version of the CES-D in the present sample was 0.83.

In order to evaluate the linkages of interest, important socio-demographic variables that are known to be significantly associated with depressive symptomatology were controlled for in all data analyses. Specifically, previous studies have shown that sex, age, marital status, education, and household income are important correlates of psychological well-being (Diener 1994). In addition, adjusting for these variables provides information which enables the development of a more comprehensive causal model. The analysis included only those background and contextual variables that had been significantly correlated to individuals' level of depression. The demographic variables included for further analysis were age, sex, marital status, level of formal education, and household income. Household income was assessed according to an 18-item scale $(1=\mathrm{HK} \$ 1,999$ or less; $2=\mathrm{HK} \$ 2,000-3,999 ; 3=\mathrm{HK} \$$
$4,000-4,999 ; 4=\mathrm{HK} \$ 5,000-5,999 ; 5=\mathrm{HK} \$ 6,000$ 6,$999 ; \quad 6=\mathrm{HK} \$ 7,000-7,999 ; \quad 7=\mathrm{HK} \$ 8,000-8,999$; $8=\mathrm{HK} \$ 9,000-9,999 ; 9=\mathrm{HK} \$ 10,000-12,499 ; 10=$ HK\$ $12,500-14,999 ; 11=$ HK\$ 15,000-19,999; $12=$ HK \$ 20,000-24,999; $13=\mathrm{HK} \$ 25,000-29,999 ; 14=\mathrm{HK} \$$ $30,000-39,999 ; \quad 15=\mathrm{HK} \$ \quad 40,000-49,999 ; \quad 16=\mathrm{HK} \$$ $50,000-59,999 ; 17=\mathrm{HK} \$ 60,000-69,999 ;$ and $18=\mathrm{HK} \$$ 70,000 and above).

\section{Analyses}

The outcome variables were CES-D scale scores at the baseline and 1-year follow-up assessment. We analyzed predictors of these scores using multiple regression and entering all variables at once, a method which is more conservative and less prone to type 1 errors than the more commonly used stepwise method. As multiple regression allows one variable to be included for every 20 observations, we had sufficient power to include 10 independent variables (Hair et al. 2005). When we used the CES-D scores at 1-year follow-up assessment as the dependent variable, the baseline scores were also included in the regression equations.

The moderating effects of poorly planned migration were evaluated for the association of depressive symptoms with stress and quality of life after controlling for socio-demographic variables (Baron and Kenny 1986). These were evaluated by using the base model, with an interaction term added between poorly planned migration and the potential moderator. Centered variables were used for poorly planned migration and the potential moderator to reduce multicollinearity due to the interaction term (Aiken and West 1991). There were moderate correlations between the predictive variables used in the regression analyses; therefore, the variance inflation factor (VIF) values of the independent variables were obtained before performing all regression models. All continuous variables were routinely standardized to reduce the multicollinearity problem. All these VIF values were lower than the common cut-off threshold of 3.0 (Miles and Shevlin 2001). As a result, the multi-collinearity between predictor variables was at an acceptable level. To conduct a sensitivity test, we used a score of 16 as the cutoff point for the CES-D to create a dummy variable, namely whether the person was depressed, and repeated the multiple regression by using logistic regression. The same results were obtained for both, so in this paper we only report the results of the multiple regression analyses.

\section{Results}

Among our respondents, there were many more women $(87.3 \%)$ than men $(12.7 \%)$. The mean age of all respondents 
Table 1 Descriptive statistics of socio-demographic variables, premigration planning, psycho-social variables, and CES-D scores $(n=347)$

\begin{tabular}{|c|c|c|}
\hline Socio-demographic variables & Percentage & Mean $(\mathrm{SD})$ \\
\hline Age (range 18-67) & & $34.1(8.7)$ \\
\hline \multicolumn{3}{|l|}{ Gender } \\
\hline Female & 87.3 & \\
\hline Male & 12.7 & \\
\hline \multicolumn{3}{|l|}{ Marital status } \\
\hline Married & 90.2 & \\
\hline Education & & $3.4(0.9)$ \\
\hline No formal education (1) & 1.7 & \\
\hline Elementary school (2) & 12.1 & \\
\hline Junior high school (3) & 42.1 & \\
\hline Senior high school (4) & 35.2 & \\
\hline Diploma (5) & 6.3 & \\
\hline University graduate (6) & 2.6 & \\
\hline Household Income in HK\$ (range 1-18) & & $7.9(3.0)$ \\
\hline Poorly planned migration (range $0-5$ ) & & $1.9(0.9)$ \\
\hline \multicolumn{3}{|l|}{ Psycho-social variables } \\
\hline Stress (range $0-128$ ) & & $30.5(19.7)$ \\
\hline Quality of life (range 60-137) & & $99.3(13.3)$ \\
\hline CES-D scores at baseline (range 0-48) & & $11.4(10.0)$ \\
\hline $\begin{array}{l}\text { CES-D scores at 1-year follow-up } \\
\text { (range } 0-42 \text { ) }\end{array}$ & & $5.8(7.6)$ \\
\hline
\end{tabular}

$C E S-D$ Center for Epidemiological Studies of Depression

was 34.1 years with a standard deviation of 8.7. The vast majority (90.2\%) were currently married. Approximately three-quarters had had a high school education (77.3\%). The median monthly household income range was HK\$ 9,0009,999, which is close to the median salary in Hong Kong (HK\$ 10,000). Our main outcome measure, CES-D scores, decreased substantially from 11.4 at baseline assessment to 5.8 at 1-year follow-up, indicating that most of the migrants who took part in the second round of interviews had improved (Table 1).

Predictors of Depressive Symptoms at Baseline Assessment

When the baseline CES-D scores were used as the dependent variable in the regression model, as can be seen in Table 2 the result was highly significant. Standardized regression coefficients and significant tests for each of the independent variables are given in Table 2. Our premigration factor, namely poor migration planning, was significantly and positively associated with the CES-D scores. Compared with those who had prepared well, immigrants who were poorly prepared for their migration to Hong Kong were more likely to report depressive symptoms. As can be seen from the table, both postmigration factors, acculturation stress and quality of life, were also significantly correlated with the CES-D scores, which is not surprising. Specifically, new immigrants who reported high levels of acculturation stress or low level of quality of life were more likely to report a high level of depressive symptoms than those who reported the reverse. Moreover, new migrants who reported a higher household income were less likely to report a high level of depressive symptoms. We also examined the moderating effects of poor migration planning in the association of depressive symptoms with acculturation stress and quality of life. The results of those two regression models revealed no significant interaction effect.

Predictors of Depressive Symptoms at 1-Year Follow-up Assessment

The multiple regression analyses were repeated using the CES-D scores at 1-year follow-up as the dependent variable, with the baseline scores added into the regression equation as one of the predictors. All three regression equations shown in Table 3 were again highly significant. Not surprisingly, the CES-D scores at baseline were positively associated with the scores at 1-year follow-up. However, poor migration planning was no longer associated with CES-D scores at this stage, although both postmigration factors were still significant predictors of the CES-D scores. Nevertheless, the two post-migration factors measured at the baseline, that is acculturation stress and quality of life, still predicted the CES-D scores at 1-year follow-up. Similarly, the two interaction terms were tested separately. We found that both of these-poorly planned migration and stress as well as poorly planned migration and quality of life-were significant.

\section{Discussion}

The experience of migration and its impact on the mental health of those who undertake it has long been the subject of research in psychiatry. Although the roles of pre- and post-migration factors in refugees' and asylum seekers' mental outcomes have been established in the literature (Birman and Tran 2008; Fenta et al. 2004; Lindencrona et al. 2008; Silove et al. 1997), no studies have focused on how the interaction between them might contribute to depressive symptoms in these migrant groups. Furthermore, no systematic examination has previously been conducted of the effect of pre- and post-migration factors on depressive symptoms for new immigrants moving for the purpose of reuniting their families, especially those who have lived in their destination country for fewer than 
Table 2 Standardized regression coefficients, $t$ and significance values for predictor variables in regression equations predicting CES-D scores at baseline assessment $(n=347)$

\begin{tabular}{|c|c|c|c|}
\hline & \multicolumn{3}{|l|}{ CES-D scores } \\
\hline & Beta $(t)$ & Beta $(t)$ & Beta $(t)$ \\
\hline \multicolumn{4}{|l|}{ Demographic variables } \\
\hline Gender & $0.065(1.640)$ & $0.065(1.630)$ & $0.066(1.650)$ \\
\hline Age & $-0.032(-0.796)$ & $-0.031(-0.754)$ & $-0.029(-0.703)$ \\
\hline Married & $0.052(1.349)$ & $0.049(1.281)$ & $0.054(1.396)$ \\
\hline Education & $0.052(1.405)$ & $0.051(1.375)$ & $0.049(1.297)$ \\
\hline Household income & $-0.099 *(-2.581)$ & $-0.097 *(-2.533)$ & $-0.098 *(-2.544)$ \\
\hline \multicolumn{4}{|l|}{ Pre-migration factor } \\
\hline Poorly planned migration & $0.131 * *(3.514)$ & $0.132 * *(3.534)$ & $0.127 * *(3.387)$ \\
\hline \multicolumn{4}{|l|}{ Post-migration factors } \\
\hline Stress & $0.314 * * *(7.921)$ & $0.306 * * *(7.617)$ & $0.312 * * *(7.859)$ \\
\hline Quality of life & $-0.490 * * *(-11.908)$ & $-0.487 * * *(-11.827)$ & $-0.484 * * *(-11.677)$ \\
\hline \multicolumn{4}{|l|}{ Interaction term } \\
\hline Poorly planned migration $\times$ stress & & $0.047(1.293)$ & \\
\hline \multirow[t]{3}{*}{ Poorly planned migration $\times$ quality of life } & & & $-0.042(-1.135)$ \\
\hline & $F(8,338)=57.143^{* * *}$ & $F(9,337)=51.081 * * *$ & $F(9,337)=50.981 * * *$ \\
\hline & $R^{2}=0.565$ & $R^{2}=0.566$ & $R^{2}=0.565$ \\
\hline
\end{tabular}

$C E S$ - $D$ Center for Epidemiological Studies of Depression, $R^{2}$ adjusted $R$ square

$* p<0.05, * * p<0.01, * * * p<0.001$

Table 3 Standardized regression coefficients, $t$ and significance values for predictor variables in regression equations predicting CES-D scores at 1 -year follow-up assessment $(n=347)$

\begin{tabular}{|c|c|c|c|}
\hline & \multicolumn{3}{|l|}{ CES-D scores } \\
\hline & $\operatorname{Beta}(t)$ & Beta $(t)$ & Beta $(t)$ \\
\hline CES-D scores at baseline & $0.187 * *(2.677)$ & $0.169 * *(2.458)$ & $0.179 *(2.557)$ \\
\hline \multicolumn{4}{|l|}{ Demographic variables } \\
\hline Gender & $-0.007(-0.137)$ & $-0.007(-0.147)$ & $-0.006(-0.108)$ \\
\hline Age & $-0.013(-0.245)$ & $-0.007(-0.141)$ & $-0.004(-0.086)$ \\
\hline Married & $0.025(0.494)$ & $0.016(0.327)$ & $0.029(0.590)$ \\
\hline Education & $-0.015(-0.313)$ & $-0.018(-0.387)$ & $-0.024(-0.490)$ \\
\hline Household income & $-0.017(-0.332)$ & $-0.012(-0.236)$ & $-0.014(-0.285)$ \\
\hline \multicolumn{4}{|l|}{ Pre-migration factor } \\
\hline Poorly planned migration & $-0.084(-1.719)$ & $-0.080(-1.655)$ & $-0.093(-1.898)$ \\
\hline \multicolumn{4}{|l|}{ Post-migration factors } \\
\hline Stress & $0.301 * * *(5.413)$ & $0.276 * * *(5.021)$ & $0.299 * * *(5.395)$ \\
\hline Quality of life & $-0.182 * *(-2.889)$ & $-0.180 * *(-2.907)$ & $-0.173 * *(-2.745)$ \\
\hline \multicolumn{4}{|l|}{ Interaction term } \\
\hline Poorly planned migration $\times$ stress & & $0.172 * * *(3.732)$ & \\
\hline \multirow[t]{2}{*}{ Poorly planned migration $\times$ quality of life } & & & $-0.097 *(-2.068)$ \\
\hline & $\begin{array}{l}F(9,337)=15.823 * * * \\
R^{2}=0.278\end{array}$ & $\begin{array}{l}F(10,336)=16.184 * * * \\
R^{2}=0.305\end{array}$ & $\begin{array}{l}F(10,336)=14.810 * * * \\
R^{2}=0.285\end{array}$ \\
\hline
\end{tabular}

$C E S-D$ Center for Epidemiological Studies of Depression, $R^{2}$ adjusted $R$ square

$* p<0.05$, ** $p<0.01, * * * p<0.001$

2 years. To address this research gap, this study has investigated the impact of one pre-migration factor, namely poor planning, and two post-migration factors, namely acculturation stress and quality of life, on depressive symptomatology; it has also sought to identify the interaction effect between pre- and post-migration factors and 
depressive symptoms. To our knowledge, the present investigation is the first study of its kind, and the first to address an understudied population, that is, Chinese immigrants to Hong Kong seeking to reunite their families. The good news from our analysis is that that depressive symptoms in such migrants have decreased significantly after 1 year of settlement in Hong Kong.

Perhaps the most important and interesting finding of this study is that poor migration planning predicts depressive symptoms reported by new immigrants who had lived in Hong Kong for fewer than 6 months, after adjusting for demographic variables, post-migration factors, acculturation stress, and quality of life. However, its direct effect on symptoms of depression had disappeared by 1 year after arrival. Even more interestingly, this factor continues to exert its impact on depressive symptoms by exacerbating the negative effects of stress and poor quality of life. Our study is the first to report this interaction effect between pre- and post-migration factors on symptoms of depression in a longitudinal study of new migrants reuniting their families. Our results highlight the importance of using such longitudinal data to investigate the dynamic interaction between pre- and post-migration factors, particularly given that most previous studies have reported on correlational data (Birman and Tran 2008; Silove et al. 1997; Ryan et al. 2006; Chou 2009). As this study shows, only longitudinal studies are able to disentangle the complex pathways which may link the interaction effects of pre- and post-migration factors to ongoing depressive symptoms. The next, and perhaps even more interesting, question is whether or not the moderating role of poor migration planning will have disappeared after 2 years of settlement in Hong Kong. We plan to re-interview our respondents a second time, 2 years after the baseline assessment, to address this important issue.

Our cross-sectional results suggest that the impact of poor migration planning on mental health among newly arrived migrants from Mainland China to Hong Kong is robust and independent of the demographic and psychosocial factors we have examined in this study, since its effect remains significant after adjustment for these. These findings are consistent with another recent study which showed poor migration planning to be significantly correlated with depressive symptoms after adjustment for demographic variables and several psychosocial factors including social support, sense of control, and optimism (Ryan et al. 2006). It is also surprising to find that a significant proportion of respondents were not well prepared for their migration to Hong Kong, even though they had waited several years after their initial application. For instance, about $8 \%$ of them did not know how long they would stay in Hong Kong and $16 \%$ of them had not prearranged accommodation. Almost one-fifth $(18.3 \%)$ of them had not prepared for their migration to Hong Kong at all. As mentioned earlier, a long waiting time might contribute to this poor planning because of the deterioration of hope, frustration, or even depression. Unfortunately, we did not measure the depressive symptoms before migration which might affect the migration planning. However, it is interesting to note that the direct impact of poor planning for migration on depressive symptoms may be significant but transient. Our findings suggest that such a harmful effect decays over time and disappears entirely after 1 year of settlement in Hong Kong. This is the first time that such findings have been reported in an Asian country, but they are consistent with previous studies in which another premigration factor, namely stressful detention conditions, exerted a short-lived effect on depressive symptoms in refugees; its impact was shown to have disappeared after a period of 2 years (Birman and Tran 2008; Beiser et al. 1989).

Even more interestingly, our results here suggest that the pre-migration factor studied here can exacerbate the harmful effect of the two post-migration factors, that is, high acculturation stress or low quality of life, on depressive symptomatology after more than a year of settlement. Chou (2009) has previously identified an interaction between pre- and post-migration factors in migrants, suggesting that adequate social support may protect those who were poorly prepared for their migration from becoming depressed. However, Chou (2009) used cross-sectional data, so the temporal sequence between social support and depressive symptoms remains uncertain. Therefore, the current study makes a unique contribution to the literature by examining this issue empirically. These findings suggest that the process of adaptation may be different for those who were well-prepared for their migration and those who were not. Specifically, those who were poorly prepared may be particularly vulnerable to the distress in the early stage of settlement in host country. Our studies are consistent with previous research on refugees, in which social support has been shown to moderate both the impact of stressful life events on life satisfaction (Young 2001) and the link between detention and depressive symptoms (Birman and Tran 2008). We have extended these previous findings to immigrants in general, especially those who have migrated in order to reunite their families. Our results indicate that a significant percentage of the new migrants in our study had not prepared well, and even though the direct impact of this on depressive symptoms has disappeared after 1 year of settlement in Hong Kong, it aggravated the detrimental effect of high stress or low quality of life. It is therefore imperative that policy makers explore ways in which to strengthen migration planning for imminent arrivals to Hong Kong so that their mental health can be improved, or at least maintained at a healthy level. 
Furthermore, we have found that both high levels of acculturation stress and low quality of life were strong predictors of symptoms of depression, in a representative sample of new Hong Kong migrants from Mainland China. Our results suggest that there is a dynamic relationship over time between these two post-migration factors and symptoms of depression. Migrants with high levels of stress and poor quality of life are more likely to report depressive symptoms than those with the reverse. All these findings are consistent with earlier theoretical considerations of the issue, which have shown that acculturation stress and quality of life are two of the six important factors that contribute to successful adjustment in the host country (Bhugra 2003; Furnham and Bochner 1986). The literature also informs us that acculturation stress is certainly a critical predictor of the successful integration of immigrants (Gonzalez et al. 2001). Nevertheless, empirical studies of these two psycho-social factors among new immigrants have not been conducted, and our findings now provide evidence to support such a model.

\section{Limitations}

In interpreting the results of the current study, it is important to consider four methodological limitations. Firstly, although this research is based upon a year of longitudinal data, the measure of poor migration planning was obtained retrospectively. Longitudinal data with multiple waves of data collection over a longer period of time, say 10 years, will be needed to fully understand the relationship between pre- and post-migration factors and depression. Moreover, quality of migration planning should ideally be assessed before people migrate. The preliminary results reported here should nevertheless encourage other investigators to examine how pre- and post-migration factors affect the mental health of new immigrants who have migrated for reasons of family reunion. Secondly, although our assessment procedures involved a broad range of variables that had previously been found to be associated with psychological distress, there are other potentially important pre- and post-migration factors that were not included. For example, the present study did not address pre-migration measures like traumatic experiences either in childhood or subsequently, depressive symptoms, stress, quality of life or social support and/or critical life events before migration because all these factors might migrants' psychological well-being in post-migration period. In addition, post-migration factors like the experience of discrimination, smoking, and alcohol use, were also not assessed. Future studies should seek to incorporate more comprehensive and adequate measures of pre- and postmigration factors. Thirdly, our sample was predominantly female. Although this reflects the gender distribution of the population of interest, our results might not be generalizable to male migrants from Mainland China to Hong Kong. Moreover, it is interesting to identify gender differences in terms of mental health outcomes, and the role of pre- and post-migration factors as well as psycho-social issues on mental health outcomes and other aspects of adjustment in Hong Kong. In future, studies of male immigrants from the Mainland to Hong Kong must be conducted so that these issues can be addressed. Finally, as mentioned earlier, our measure of depression was based on a self-report of current symptoms rather than expert-administered diagnostic interviews of clinical symptoms that would have probably yielded more accurate clinical information. Therefore, our results may not generalize to the clinical diagnosis of depression.

\section{Conclusions}

Even with these limitations, however, the findings presented in this study contribute to resolving the puzzle of the predictors of mental health among new immigrants from Mainland China to Hong Kong. Such research can facilitate better-informed modification and enhancement efforts related to mental health interventions for this group. The dataset provides us with the opportunity to examine the causes of psychological distress while considering a wide range of psycho-social risk factors. Preventive measures must be designed for new immigrants, especially those who did not prepare well. Our findings also suggest that am enhancement of quality of life and reduction of acculturation stress might be effective intervening factors for preventive measures.

Acknowledgments This work was funded by the Research Grant Council, Public Policy Research Funding Scheme (HKU 7004PPR20051).

Open Access This article is distributed under the terms of the Creative Commons Attribution Noncommercial License which permits any noncommercial use, distribution, and reproduction in any medium, provided the original author(s) and source are credited.

\section{References}

Aiken, L. S., \& West, S. G. (1991). Multiple regression: Testing and interpreting interactions. Newbury Park: Sage Publications.

Baron, R. M., \& Kenny, D. A. (1986). The moderator-mediator variable distinction in social psychological research: Conceptual, strategic, and statistical considerations. Journal of Personality and Social Psychology, 51, 1173-1182.

Beiser, M., Turner, R. J., \& Ganesan, S. (1989). Catastrophic stress and factors affecting its consequences among Southeast Asian refugees. Social Science and Medicine, 28, 183-195.

Bhugra, D. (2003). Migration and depression. Acta Psychiatrica Scandinavica, 108, 67-72. 
Birman, D., \& Tran, N. (2008). Psychological distress and adjustment of Vietnamese refugees in the United States: Association with pre- and postmigration factors. American Journal of Orthropsychiatry, 78, 109-120.

Chan, S. W. C., Chiu, H. K. F., Chien, W. T., Thompson, D. R., \& Lam, L. (2006). Quality of life in Chinese elderly people with depression. International Journal of Geriatric Psychiatry, 21, 312-318.

Chou, K. L. (2009). Pre-migration planning and depression among new migrants to Hong Kong: The moderation role of social support. Journal of Affective Disorders, 114, 85-93.

Chou, K. L., \& Chi, I. (2001). Stressful events and depressive symptoms among old women and men: A longitudinal study. International Journal of Aging and Human Development, 51, 275-293.

Diener, E. (1994). Subjective well-being. Psychological Bulletin, 95, $542-575$.

Fenta, H., Hyman, I., \& Noh, S. (2004). Determinants of depression among Ethiopian immigrants and refugees in Toronto. Journal of Nervous and Mental Disease, 192, 363-372.

Furnham, A., \& Bochner, S. (1986). Cultural shock: Psychological reactions to unfamiliar environments. London: Methuen.

Gonzalez, H. M., Hann, M. N., \& Hinton, L. (2001). Acculturation and the prevalence of depression in older Mexican Americans: Baseline results of the Sacramento area Latino study on aging. Journal of the American Geriatric Society, 49, 948-953.

Hair, J. F., Black, B., Babin, B., \& Anderson, R. E. (2005). Multivariate data analysis (7th ed.). Upper Saddle River: Pearson/Prentice Hall.

Hovey, J. D., \& Magana, C. (2000). Acculturative stress, anxiety, and depression among Mexican immigrant farm workers in the Midwest United States. Journal of Immigrant Health, 2, 119131.
Lindencrona, F., Ekblad, S., \& Hauff, E. (2008). Mental health and recently resettled refugees from the middle east in Sweden: The impact of pre-resettlement trauma, resettlement stress and capacity to handle stress. Social Psychiatry and Psychiatric Epidemiology, 43, 121-131.

Miles, J. N., \& Shevlin, M. E. (2001). Applying regression and correlation: A guide for students and researchers. London: Sage Publications.

Radloff, L. S. (1997). The CES-D scale: A self-report depression scale for research in the general population. Applied Psychological Measurement, 1, 385-401.

Ryan, L., Leavey, G., Golden, A., Blizard, R., \& King, M. (2006). Depression in Irish immigrants living in London: Case-control study. British Journal of Psychiatry, 188, 560-566.

Silove, D., Sinnerbrink, I., Field, A., Manicavasagar, V., \& Steel, Z. (1997). Anxiety, depression and PTSD in asylum-seekers: Associations with pre-migration trauma and post-migration stressors. British Journal of Psychiatry, 170, 351-357.

United Nations. (2006). World Economics and Social Survey 2006: Diverging growth and development. http://www.un.org/esa/ policy/wess/wess2006files/wess2006.pdf. Accessed 16 Dec 2008.

Wong, D. K. F., Lam, D., Yan, P., \& Hung, M. (2004). The impacts of acculturative stress and social competences on the mental health of Mainland Chinese immigrant youth in Hong Kong. British Journal of Social Work, 34, 1009-1024.

World Health Organization Quality of Life Group. (1998). Development of the World Health Organization WHOQOL-BREF Quality of Life Assessment. Psychological Medicine, 28, 551558.

Young, M. Y. (2001). Moderators of stress in Salvadoran refugees: The role of social and personal resources. International Migrant Review, 35, 840-869. 